\title{
A ESCUTA DO SUJEITO NO CONTEXTO DE RECURSOS HUMANOS*
}

\author{
Maria Cristina Poli \\ da Universidade Veiga de Almeida. \\ Lucia Almeida \\ da MSA Consultoria em Recursos Humanos.
}

\begin{abstract}
Resumo: A partir da análise das atribuições da área de Recursos Humanos, propomos promover um debate interdisciplinar em um diálogo com a psicanálise. Entendemos que os estudos sobre as organizações têm trazido inúmeras contribuições, auxiliando as empresas em sua busca por espaços de trabalho mais humanizados. Porém, não queremos deixar de problematizar o modo como as empresas lidam com seus funcionários, na medida que elas podem produzir um modelo instrumentalizado e instrumentalizador, com tal rigor pragmático e metodológico que acaba inviabilizando a escuta do trabalhador de um outro lugar senão o de agente de padronização a serviço dos objetivos da empresa.

Palavras-chave: Psicanálise. Cultura. Recursos humanos. Trabalho.
\end{abstract}

Nesses últimos vinte anos, atuamos na área de Recursos Humanos $(\mathrm{RH})$ dentro de empresas dos mais diferentes segmentos de mercado. Ao longo desse período, fomos compreendendo que a função essencial dessa área é atender aos objetivos estratégicos da empresa, através dos processos e instrumentos aplicados à gestão de $\mathrm{RH}$ que acena para uma possibilidade de garantia de sobrevivência da empresa através das pessoas.

Analisando os subsistemas de $\mathrm{RH}$ - quais sejam: recrutamento e seleção; treinamento e desenvolvimento; avaliação de desempenho; cargos e salários; qualidade de vida no trabalho; relações institucionais etc. -, verificamos uma configuração de conceitos e práticas que levam à

\footnotetext{
* Artigo recebido em 25/10/2012 e aprovado em 18/01/2013.
} 
associação entre o incremento da performance do trabalhador e sua satisfação no trabalho. Em nossa experiência profissional, contudo, o que pudemos perceber é um distanciamento entre os resultados esperados dessas ações e o que se traduz em realidade.

Essa percepção pode ser auferida a cada aplicação dos subsistemas, como, por exemplo, nos processos de recrutamento e seleção. As tecnologias atuais de avaliação de seleção sugerem a aplicação de métodos quantitativos, com vista a reduzir a subjetividade do recrutador, como seleção por competências (LEME, 2007). Porém, na prática, a avaliação de um candidato é composta de outros aspectos, como a adequação à cultura da empresa, aos futuros desafios profissionais, o histórico familiar, entre outros que surgem de uma abordagem menos matemática do candidato. Sendo assim, se aquilo que diferencia um candidato de outro é a sua singularidade, perguntamos como não escutá-lo para além dos dados objetivos de evidências comportamentais e experiências profissionais.

Em muitas entrevistas individuais e dinâmicas de grupo, por nós realizadas, pudemos registrar algumas falas de candidatos, tais como: "Existe vida após o trabalho"; "É importante separar a vida profissional da pessoal"; "Precisamos ter um tempo depois do trabalho para se fazer aquilo que se gosta".

A partir dessas falas, extraídas da exposição dos candidatos sobre suas expectativas pessoais e profissionais no contexto de avaliação, nos questionamos sobre as consequências para o processo de $\mathrm{RH}$, se não as considerarmos em nossa avaliação. Quais os resultados de nosso trabalho se não levarmos em conta aquilo que o candidato traz como significantes de sua relação com o trabalho e em relação a outros fatores atinentes a seu universo familiar e escolhas pessoais?

Ao acompanhar os trabalhadores em suas questões profissionais e, também, naquelas de cunho mais pessoal, percebe-se que a função da escuta (nos processos de seleção, avaliação de desempenho, treinamento) fica à deriva, não havendo porto seguro que acolha a fala do funcionário dentro das organizações. Isso é, não há uma prática habitual de acolhimento desses elementos subjetivos por parte dos profissionais que se dizem agentes da melhoria das relações humanas no trabalho.

Nas possibilidades que se apresentam, dentro dos subsistemas de $\mathrm{RH}$, temos atuado apoiando-nos na escuta dos trabalhadores para além dos dados quantitativos esperados, e traduzindo essas falas em ações concretas de melhoria de processos e relações de trabalho. Influenciadas pela teoria psicanalítica em função de nossa atuação clínica, surpreendemo-nos, muitas 
vezes, acolhendo a fala do trabalhador para além do que seria esperado de nossa atuação como profissional de $\mathrm{RH}$. A partir daí, nos propusemos a mergulhar na questão da escuta analítica nesse contexto de trabalho, acreditando que poderemos contribuir para o aprimoramento de outros profissionais da área.

Para fundamentar nossa direção de trabalho, apresentaremos, na sequência, um contraexemplo que chocou o mundo e que faz com que as áreas de $\mathrm{RH}$ precisem repensar suas rotinas. Referimo-nos à série de suicídios ocorridos entre os funcionários da France Télécom, na França, o que se apresenta como uma evidência indiscutível das consequências do mundo empresarial sobre o trabalhador e da importância da sustentação dessa função de escuta e acolhimento dentro das empresas. A partir desse caso, esperamos melhor compreender alguns dos diversos impasses do sujeito diante das múltiplas representações do trabalho: o trabalho como base de valoração do homem, como sofrimento, como definição do que se é perante a sociedade e suas relações.

\section{UM CASO EXEMPLAR: FRANCE TÉLÉCOM}

A France Télécom foi considerada a principal empresa francesa de

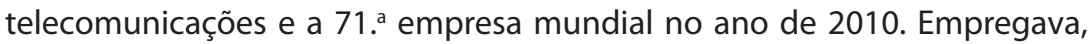
então, quase 187.000 pessoas, das quais cerca de 100.000 na França, atendendo cerca de 174 milhões de clientes no mundo.

Acompanhemos um pouco de sua história apresentada por Garric (2010). Para responder a uma diretiva europeia de colocação em concorrência dos serviços públicos nacionais, a antiga Direction Générale des Télécommunications (DGT) torna-se a France Télécom em 1. ${ }^{\circ}$ de janeiro de 1988 . Em julho de 1990, a lei instituída para fins de mudança de administração transforma a France Télécom em uma empresa de direito público, dotada de uma personalidade moral distinta do Estado e com autonomia financeira. Em setembro de 2004, o Estado francês vende uma parte das suas ações, para reduzir seu nível abaixo dos 50\%, transformando a France Télécom, de forma definitiva, em uma empresa privada.

Após essa transição de capital e administração, o que ocorre não é apenas uma mudança no modelo administrativo-financeiro da empresa. Antes, havia uma instituição pública com códigos de conduta, valores, vínculos de trabalho e relações humanas próprias a esse tipo de empresa. Ao transformar-se em uma instituição privada, surgem novas regras, valores, vínculos e uma drástica alteração estratégica do posicionamento da gestão de seus empregados. 
Talvez o elemento mais significativo tenha sido as técnicas utilizadas para obrigar os empregados a deixarem a companhia, como transferências forçadas para outras regiões e mudanças nas atividades e cargos dos funcionários. O programa denominado Éhora de se mover obrigava os gestores a mudar de profissão ou de área geográfica a cada três anos. Seus empregados, da mesma forma, foram compelidos a se filiar a essa nova instituição (privada), sem que tenham feito uma escolha por ela, tendo que se submeter a códigos de competitividade e rotatividade que desconheciam. Essas, entre outras modificações no modelo de gestão dessa empresa, foram reconhecidas como as causas de depressão e outros problemas psicológicos em seus funcionários, e estariam ligadas também aos dramáticos acontecimentos de 2008 a 2010.

Nesse período, ocorreram mais de trinta suicídios entre os trabaIhadores e mais de vinte tentativas. A empresa admitiu que as mudanças organizacionais necessárias durante a transição de uma companhia estatal para uma multinacional competitiva poderiam ser consideradas estressantes e ter motivado os suicídios e demais estados psicológicos alterados.

Segundo o sindicato SUD-Solidaires, um dos empregados que se suicidou tinha sido transferido recentemente e não se sentia bem no seu novo serviço, "do qual se libertou", segundo sua carta de despedida. Patrice Diochet, membro de um dos sindicatos ligados à France Télécom, reagiu à notícia dizendo: "É aterrorizante. Ele trabalhava numa seção conhecida há muito tempo por ser insuportável; havia uma verdadeira indiferença, nenhum calor humano, não se falava senão de números. Os empregados eram carne para canhão".

Outra funcionária se jogou do quarto andar do prédio da empresa, depois de uma reunião de trabalho em que lhe foi comunicado que mudaria de função. O marido da vítima, um executivo sênior, escreveu uma carta acusando a empresa de ser responsável pelo gesto de sua esposa.

"Suicido-me devido ao meu trabalho na France Télécom. É a única causa." O autor dessa frase desesperada, um empregado de 51 anos, pôs termo aos seus dias em seu domicílio, em Marselha. Na carta deixada a sua família, cujo conteúdo foi comunicado, de acordo com a sua vontade, aos seus colegas e aos delegados dos trabalhadores (representantes sindicais na empresa), ele evoca nomeadamente "a urgência permanente", "a sobrecarga de trabalho", "a ausência de formação", "a desorganização total da empresa" e "a gestão do terror".

Outro empregado escreve: "Aquilo desorganizou-me totalmente e perturbou-me. Tornei-me um barco naufragado, é melhor terminar". 
A direção da empresa confirmou os suicídios, mas não teceu comentários sobre o conteúdo das cartas, relatando somente a importância de se tentar compreender o que se passou e recordando que as causas de um suicídio podem ser, sempre, múltiplas. A empresa afirmou ainda que dias antes de alguns dos suicídios, os colegas dos empregados e os seus responsáveis observaram sinais de depressão.

Um dos delegados dos trabalhadores tinha alertado sobre o malestar de um dos empregados suicidas e a empresa tentou diminuir o volume de seu trabalho, conforme informado por Denis Capdevielle, delegado dos trabalhadores do Comitê de Higiene, Segurança e Condição de Trabalho (CHSCT). "Mas o seu mal-estar devia ser profundo", acrescentou.

Durante bastante tempo, os sindicatos dos trabalhadores denunciaram o estresse decorrente das condições de trabalho na France Telecom. Além das mudanças realizadas na gestão, os empregados estavam sendo pressionados à demissão voluntária para atender a um plano de reestruturação. Entre 2005 e 2008 ocorreram mais de 22.000 "partidas voluntárias".

Fabienne Viala, representante de um dos sindicatos, denunciou sobrecargas de trabalho ligadas à baixa de efetivos e a responsabilidades cada vez mais pesadas, principalmente para as chefias, como era o caso de um dos empregados falecidos.

Diante desse quadro, a direção da France Télécom instaurou um dispositivo de acompanhamento e escuta para os colegas envolvidos nas perdas. Cabe aqui a pergunta se, no entanto, esse dispositivo não deveria ter surgido bem antes, no momento em que houve a decisão da privatização.

Os representantes de seis sindicatos envolvidos com a empresa recobraram as esperanças, ao serem recebidos em uma reunião pelo diretor de Recursos Humanos, Olivier Barberot. Um deles saiu da reunião dizendo: "Começa a haver uma escuta na France Télécom ...." Na véspera desse encontro, a direção tentava minimizar o sentido desses suicídios, mas a pressão e os alertas foram finalmente entendidos. Todos saíram da reunião com vários compromissos de multiplicação das iniciativas. Foi criada a "Comissão Estresse" no CHSCT, a formação dos gerentes para a detecção dos sinais de fragilidade em seus empregados (índices que levam à suspeita de que um servidor encontra-se em dificuldade), além de se abrir espaços de escuta e de acompanhamento.

Todavia, apesar de todos os esforços, após algum tempo, o acompanhamento dessas ações acordadas foi criticado pelos sindicalistas. Eles denunciavam a falta de reuniões da comissão para redução do estresse, assim como a inoperância da escuta realizada pelos gestores, visto que os 
empregados se sentiam intimidados em relatar seus problemas frente aos seus superiores hierárquicos.

A empresa insistiu no acompanhamento dos empregados através de seus setenta médicos do trabalho e seus quarenta assistentes sociais. Porém reconheceram que não eram bastante numerosos.

Sabemos que é da essência do homem o conflito e certo grau de insatisfação. Assim, em um ambiente empresarial, é crucial perceber em que bases foram estabelecidas as identificações para a formação dos grupos e o quanto o trabalho - através de seus códigos, proibições e exigências - amarra o funcionário, de forma que a única saída para dar conta dessa renúncia seja a agressão contra si mesmo ou contra o outro, como nesse caso.

Entendemos que é a partir da escuta dos significantes singulares a cada profissional que podemos apontar para uma possibilidade de ações que mantenham, minimamente, os investimentos libidinais sustentando um lugar seguro na realidade.

Em termos preventivos necessários a toda atuação na saúde pública, nos perguntamos se a área de Recursos Humanos da France Télécom instaurou algum dispositivo para identificar quais os impactos que essa mudança poderia gerar - e que, efetivamente, acabou gerando - em seus trabalhadores. Questionamo-nos, ainda, se a área de Recursos Humanos teria autoridade para agir estrategicamente nesse processo e minimizar os impactos que, por certo, teriam sido identificados com antecedência.

A atuação do profissional de Recursos Humanos precisa ser estabelecida, estruturada e antecipatória na escuta da organização e de seus trabaIhadores. Sua atuação traz um grande diferencial na forma da organização do trabalho, nos processos de mudança e de outras ações que envolvem pessoas, de modo a apoiar e direcionar as demandas dos trabalhadores às instâncias passíveis de ação.

A importância e o significado que o trabalho tem sobre o sujeito pode variar dentro de culturas diferentes, posições hierárquicas, condições sociais e econômicas. $O$ trabalho nomeia o sujeito, por vezes, mais do que sua vida familiar, qualificando-o inclusive subjetivamente.

\section{A escuta do SUJeITO COMO ESTRATÉGIA DE RH}

No livro O artífice, o autor Richard Sennett (2009) menciona que na época anterior à Revolução Industrial, o artesão e o produto do seu trabalho eram um só. Aquilo que era produzido levava a marca de seu autor. Após a Revolução Industrial, cada vez mais o homem se distanciou do produto final do seu trabalho e, muitas vezes, desconhecendo o impacto de suas ações 
naquilo que produz. Assim, também a marca pessoal que advém de seu desejo e singularidade ficou perdida, fragmentada em processos, hierarquias de responsabilidade e distanciamento. O sujeito torna-se, dessa maneira, um espectro daquilo que é, assujeitado e alienado às relações da cadeia produtiva do trabalho e suas formas de intra e inter-relação.

A escuta do trabalhador - isso é, o acolhimento e inscrição no ambiente de trabalho dos significantes que marcam sua posição subjetiva - pode ser uma importante diretriz da atuação do profissional de Recursos Humanos. Nesse contexto alienante do mundo empresarial, a escuta pode ser proposta como instrumento fundamental para a redução dos impactos subjetivos que a renúncia pulsional acarreta. Ainda mais que, via de regra, tal renúncia se dá a serviço dos interesses da empresa.

Como sabemos, a psicanálise tem como alguns de seus recursos para a investigação os lapsos, os atos falhos, os chistes, os comportamentos repetitivos; e, por vezes, o próprio silêncio que se instala pode ser eloquente de uma expressão de sofrimento psíquico. Não temos a pretensão de incluir nos subsistemas de $\mathrm{RH}$ uma proposta de tratamento psicanalítico. Trata-se, antes, de escutar algo de singular que se produz para além do objeto de intervenção proposto pelos subsistemas de $\mathrm{RH}$.

É preciso, portanto, aprofundar o que entendemos por "escuta" em psicanálise, de forma a abranger os seus benefícios no ambiente organizacional.

A escuta tem um espaço medular na psicanálise. Não importa se as palavras vêm maquiadas de mentiras ou silêncios, mas são, sim, portas que se abrem para uma possibilidade de interpretação e levantamento de hipóteses acerca do sujeito. Dessa forma, também na empresa, podemos tecer hipóteses sobre o discurso do trabalhador, sobre sua posição subjetiva, desde que haja um interlocutor atento e preparado para tal, conforme indica Lacan em um texto que muito nos inspira nessa proposta:

Quer se pretenda agente de cura, de formação ou de sondagem, a psicanálise dispõe de apenas um meio: a fala do paciente. A evidência desse fato não justifica que se o negligencie. Ora, toda a fala pede uma resposta. Mostraremos que não há fala sem resposta, mesmo que depare apenas com o silêncio, desde que ela tenha um ouvinte, e que é esse o cerne de sua função em análise. (LACAN, 1998, p. 248)

Acreditamos que a utilização apropriada das ferramentas existentes na atuação da área de Recursos Humanos - como em recrutamento e seleção, treinamento, avaliação de desempenho ou na entrevista de desligamento propicia ao trabalhador um espaço de posicionamento diante das variáveis a 
que está submetido. Sua fala, seus silêncios e suas ações, produzidos nesses momentos, nos indicam a direção que podemos seguir diante das hipóteses levantadas a partir desse posicionamento.

Caminhar no sentido de desvelar a "fala" (entendida aqui no sentido amplo indicado acima) do trabalhador na empresa é um percurso árduo que indica algumas arestas. Aquilo que temos condição de "escutar" dentro das empresas são apenas pistas que, por vezes, podem ser enganadoras ou encobridoras de outras questões. Isso porque, com certeza, há mais a ser dito, porém o espaço que se delega à fala no ambiente de RH é, em essência, restritivo a uma exposição maior do trabalhador.

Mesmo assim, algo ali pode ser dito e o é, basta haver alguém disposto a acolhê-lo. Estamos constantemente diante do trabalhador, seja pela via da observação direta no exercício de sua função, seja junto ao seu supervisor, ou pelas possibilidades abertas nos sistemas de RH. Em algum momento, sabemos que o sujeito e seu desejo irão comparecer e que, para sermos efetivos em nossa ação de escuta e direcionamento de demanda, devemos estar atentos.

Através dos lapsos, chistes, esquecimentos, das frases contraditórias, do duplo sentido, revela-se o que, aparentemente, seria um "sem sentido" no discurso do trabalhador. Como quando um entrevistado ao falar de seu chefe o chama de "paitrão" e ri pela palavra que formou. Logo após, quando questionado sobre esse neologismo, responde que o chefe tem comportamentos com ele que o faz lembrar seu pai e isso o incomoda, trazendo problemas de relacionamento que, consequentemente, repercutem em seu desempenho.

Não podemos (e nem devemos) propor nas empresas a associação livre, regra fundamental para a situação analítica, mas podemos aproveitar espaços da fala do trabalhador e esperar que algo compareça em algum momento. Mais do que isso, estar disponível para ouvi-lo quando esse momento acontecer.

Diria então que, do lugar do analista, se escuta tudo, para poder escutar alguma coisa. Coisa essa que é o inconsciente, que no seio da repetição insiste para ser escutado, que na trama dos movimentos imaginários se disfarça, se fantasia e, no entanto, vai tecendo o fantasma. (ALONSO, 2010)

Entretanto, existem riscos nessa conduta de escuta nas empresas. Para ilustrar, relatamos o caso de uma fábrica em que alguns trabalhadores reclamaram de uma psicóloga que parecia "investigar" os seus pensamentos, fazendo-lhes perguntas "sem sentido", longe do contexto do trabalho. 
Questionada sobre sua atuação, a psicóloga relatou que estava buscando informações importantes para entender o baixo desempenho dos mesmos, mas o que aconteceu foi exatamente o contrário. Tendo em vista seu modo de se portar nas entrevistas, percebida como invasiva, a resistência se instalou não só entre esses trabalhadores como também nos demais que acabaram sabendo do ocorrido.

Esse exemplo nos permite esclarecer que, para obtermos as respostas que queremos, importa o modo como nos colocamos. Não precisamos - nem devemos - ser invasivos. É necessário criar um ambiente favorável para que o trabalhador possa se colocar com maior espontaneidade dentro de dinâmicas próprias ao ambiente de trabalho. Buscaremos, assim, acolhê-lo e escutá-lo no exercício de sua função, ou nos grupos de discussão. Nesses contextos é que o sujeito comparece na sua fala.

Outro risco é fazer hipóteses de forma precoce, sem que as mesmas sejam minimamente aprofundadas e consideradas a partir de outras variáveis. Tendo em vista que nas empresas time is money, o tempo que utilizamos para o RH é reduzido. Não há como trabalhar, como em uma psicanálise, seguindo de perto as repetições derivadas da insistência da pulsão.

Temos, então, um grande paradoxo da função do RH. Como posicionar o ser humano em um complexo sistema de valores científicos, previsíveis e controlados, tendo como grande protagonista desse sistema um ser relativo, complexo e instável? Além disso, um ser em relação, histórico, em constante devir?

Um conceito importante dentro do campo da fala e da escuta é o da transferência. A fala em questão é sempre endereçada; o analisando endereça ao analista seu desejo de forma a não reconhecer a falta. Mas o analista permite esse endereçamento para que, na sua presença, o desejo possa deslizar entre os significantes e, desse modo, possibilitar simbolizações estruturantes.

Isso só é possível por conta da renúncia narcísica do analista, o que o remete a sua própria análise. Então, para que o analista possa "sobreviver" a esse lugar promotor de angústia, é fundamental que tenha passado por sua análise pessoal, pois, assim, ele poderá sustentar a transferência sem que sua história seja confundida com a história do paciente e, como consequência, sua condição de escuta fique comprometida.

Conforme nossa experiência, podemos afirmar que esse processo transferencial ocorre também na empresa. Ali, porém, o profissional de RH não está protegido pelas regras que regem o espaço analítico. Tampouco esse profissional tem, necessariamente, a formação adequada, a começar 
pela análise pessoal, para que possa se posicionar de um modo profícuo para a escuta do sujeito.

Essas são questões que ficam como pontos de atenção, pois é fato que Freud privilegia a palavra como porta de acesso ao inconsciente e, assim sendo, a escuta se instaura como o decodificador para esse desconhecido que se apresenta e se ausenta, a partir da fala, cuja produção é singular a cada ser humano.

\section{CONCLUINDO}

O desenvolvimento industrial teve, como aspecto mais óbvio, a expansão global do trabalho não apenas no que diz respeito à especialização da indústria, mas também à difusão mundial de tecnologias de máquinas, afetando a vida cotidiana e influenciando o caráter genérico da interação humana com o meio ambiente material.

Como resultado, evidenciamos a ansiedade nos processos de mudanças organizacionais, quando são inseridos novos padrões de trabalho, ou nos movimentos da economia que têm, como consequência, reestruturações não só verticais como horizontais. Aquilo que se entendia como certeza de atendimento de expectativas se traduz como também submetido a incertezas, seja pela via das demandas diferenciadas do mercado, seja pelo desenvolvimento tecnológico.

De forma mais intensa, pudemos observar esse fenômeno no caso da France Télécom, quando de sua reestruturação não só funcional mas cultural, impactando tanto aqueles que foram desmobilizados imediatamente, quanto os que permaneceram na organização, visto que há uma identificação direta destes últimos com os primeiros, ou seja, "se aconteceu com o outro pode acontecer comigo".

Nesse momento - em que não existem certezas das respostas adequadas às necessidades do trabalhador -, vem à tona a fragilidade da confiança básica, inaugural da primeira infância e necessária a um trabalho de transferência. Uma intervenção mínima de escuta, por parte dos profissionais de Recursos Humanos, parece-nos que traria resultados de, no mínimo, amparo e acolhimento desse trabalhador. Desvelaria a ele uma visão mais reflexiva do trabalho e do seu papel dentro desse contexto, além de trazer outra perspectiva sobre o trabalho e suas relações, dando-lhe a possibilidade de acolher as contingências sem ficar tão afeito à rotina. Afinal, na vida só temos uma certeza: tudo muda.

Enfim, a rotina exige uma vigilância constante e um refazer contratual entre indivíduos que também precisa ser constante, de forma que - caso 
o contrato seja quebrado - o transbordamento inevitável de sentimentos (como mágoa, perplexidade e traição, junto com suspeita e hostilidade) seja amenizado.

Considerando esse cenário, Richard Sennett (1999), em seu livro $A$ corrosão do caráter, indica que o novo capitalismo é marcado pelo mercado global e o uso maciço de novas tecnologias que tornam a vida mais dinâmica, obrigando as pessoas a se prepararem para frequentes mudanças, incluindo trocas de emprego. Ainda segundo Sennett, as empresas se caracterizam pela "força dos laços fracos". O emprego passa a ser utilitário e sem vínculo. Há uma falta de perspectiva de compromisso duradouro com a empresa, o que gera uma certa falta de lealdade institucional; os trabalhadores tendem a ficar "negociáveis", assim que descobrem que não podem contar com a empresa. Enfim, o mundo anterior ao"novo capitalismo" era mais burocrático, previsível. $\mathrm{O}$ atual tem a marca da flexibilidade e do dinamismo, das relações fluidas. A rotina é de outra ordem, não mais das certezas de realização de uma tarefa de forma repetida ou da manutenção de relacionamentos duradouros; passa a dar lugar à falta de segurança no emprego, ao futuro incerto, à costumeira reavaliação da carreira, e essa "rotina dinâmica" é tão ou mais destrutiva quanto a anterior.

Para minimizar os impactos dessa nova demanda de dinamismo e enfrentamento de incertezas, as empresas se tornaram, elas próprias, mais flexíveis a partir do remodelamento de sua gestão. Atentas às demandas do mercado, as organizações se reinventam de forma contínua, mobilizando e desmobilizando recursos a cada novo desafio.

O trabalho se torna ilegível no capitalismo flexível, porque há perda da identificação entre o ato e o ator do trabalho. $O$ trabalho passa a ser frio, mecânico, asséptico. A alienação e a indiferença, no que se refere ao produto do trabalho, se instauram e o trabalhador não tem mais o domínio do processo, não sabe mais o seu ofício original, ou o seu valor no processo produtivo, o que acarreta identificação fluida com o trabalho.

Uma nova ética profissional se estabelece no trabalho em equipe, em que se destaca a capacidade de ouvir e de se adaptar às diversas circunstâncias exigidas no ambiente interno e externo, sendo necessário maior cooperativismo. Porém, em muitos casos, o que poderia ser um catalisador para um retorno aos vínculos mais densos se traduz na evitação desses vínculos, em que os grupos tendem a se manter juntos na superfície das coisas. Conforme afirma o autor: "O trabalho em equipe deixa o reino da tragédia para encenar as relações humanas como uma farsa" (SENNETT, 1999, p. 91). 
Outro ponto desse momento na ordem do trabalho é que o fracasso não é mais a perspectiva apenas dos pobres ou desprivilegiados; tornou-se mais conhecido como um fato regular na vida da classe média. Um mito que produz angústia ao trabalhador é que o vinculo de trabalho é para sempre. Não há uma visão transitória de relação, por isso tanta mágoa envolvida nas demissões e transferências. A empresa se apropria não só do trabalhador como do seu desejo, e quando a relação utilitária já não é mais produtiva, o vínculo se rompe e se rompe o mito, despedaçando o trabalhador em sua existência.

A partir dessas questões da atualidade, o que fica de alerta é a exigência de maleabilidade por parte do sujeito, ou de um incremento na capacidade de resistir à pressão das situações adversas dentro das organizações. Acreditamos que uma gestão de $\mathrm{RH}$ mais voltada para a escuta do trabalhador pode ajudá-lo a estar preparado para enfrentar um constante correr de riscos, a partir do estabelecimento de relações mais flexíveis, em todos os níveis.

Assim, entendemos que diante da destruição da esperança e do desejo, a preservação da voz ativa do trabalhador é a única maneira de tornar o sofrimento suportável. A aposta do lugar de escuta ofertada pelo profissional de RH será de que, por meio de uma fala endereçada à transferência, o trabalhador possa encontrar uma saída desse lugar de angústia através da expressão da palavra.

\section{LISTENING TO THE SUBJECT IN THE CONTEXT OF HUMAN RESOURCES}

ABSTRACT: Based on an analysis of the attributions of the field of Human Resources, we propose an interdisciplinary debate in dialogue with psychoanalysis. We understand that studies on organizations have greatly contributed towards helping companies establish more human working spaces. Nevertheless, we consider it important to problematize how companies deal with their employees as they could produce an instrumentalized and instrumentaling model with such pragmatic and methodological rigor that it ends up influencing employees capacity to listen, making them into mere agents of standardization at the service of corporate objectives.

KEYWORDS: Psychoanalysis. Culture. Human Resources. Labor.

\section{EL ESCUCHAR AL INDIVIDUO EN EL CONTEXTO DE RECURSOS HUMANOS}

Resumen: A partir del análisis de las atribuciones del área de Recursos Humanos, proponemos promover un debate interdisciplinario en un diálogo con el psicoanálisis. Endendemos que los estudios sobre las organizaciones han traído innumerables contribuciones, auxiliando a las empresas en su búsqueda por espacios de trabajo 
más humanizados. No obstante, no queremos dejar de problematizar la forma como las empresas lidian con sus funcionarios, en la medida en que ellas puedan producir un modelo instrumentalizado e instrumentalizador, con tal rigor pragmático y metodológico, que acaben inviabilizando el escuchar al trabajador desde otra posición diferente de la de un agente de patronización a servicio de los objetivos de la empresa.

Palabras Claves: Psicanálisis. Cultura. Recursos Humanos. Trabajo.

\section{REFERÊNCIAS}

ALONSO, S. L. A escuta psicanalítica. Disponível em: http://www2.uol.com.br/percurso/ main/pcs35/35Alonso1.htm.27/06/2010. Acesso em: 27 jun. 2010.

ANTUNES, R. Os sentidos do trabalho: ensaio sobre a afirmação e a negação do trabalho. São Paulo: Boitempo, 2007.

DAVEL, E.; VASCONCELOS, J. (Org.). Recursos humanos e subjetividade. Petrópolis: Vozes, 1996.

FREUD, S. Totem e tabu. Obras completas. v. XIII. Rio de Janeiro: Imago Editora, [1913]1974.

FREUD, S. Sobre o narcisismo: uma introdução. Obras completas. v. XIV. Rio de Janeiro: Imago Editora, [1914]1974.

FREUD, S. Psicologia das massas e análise do Eu. Obras completas. v. XVIII. Rio de Janeiro: Imago Editora, [1921]1974.

FREUD, S. O futuro de uma ilusão. Obras completas. v. XXI. Rio de Janeiro: Imago Editora, [1927]1974.

FREUD, S. O mal-estar da civilização. Obras completas. v. XXI. Rio de Janeiro: Imago Editora, [1929]1974.

GARRIC, A. Cinq nouveaux suicides à France Telecom. Disponível em: http://www.lemonde. $\mathrm{fr} /$ societe/article/2010/09/10/cinq-nouveaux-suicides-en-quinze-jours-le-malaise-perdure-chez-france-telecom_1409659_3224.html. Acesso em: 18 set. 2010.

HENRIQUEZ, E. et al. A instituição e as instituições. São Paulo: Casa do Psicólogo, 1989. HENRIQUEZ, E. A organização em análise. Petrópolis: Vozes, 1997.

JERUSALINSKY, A. et al. O valor simbólico do trabalho e o sujeito contemporâneo/ APPOA (Associação Psicanalítica de Porto Alegre). Porto Alegre: Artes e Ofícios, 2000.

LACAN, J. Função e campo da fala e da linguagem em psicanálise. In: Escritos. Rio de Janeiro: Jorge Zahar Editor, 1998. p. 238-324.

LEME, R. Seleção e entrevista por competências com o inventário comportamental - Guia prático do processo seletivo para redução da subjetividade e eficácia na seleção. Rio de Janeiro: Qualitymark, 2007. 
SENNETT, R. A corrosão do caráter - consequências pessoais do trabalho no novo capitalismo. Rio de Janeiro: Record, 1999.

SENNETT, R. O artífice. Rio de Janeiro: Record, 2009.

MARIA CRISTINA POLI: professora do Mestrado Profissional Interdisciplinar Psicanálise, Saúde e Sociedade na Universidade Veiga de Almeida - RJ e do Programa de Pós-Graduação em Teoria Psicanalítica da UFRJ; analista-membro da Associação Psicanalítica de Porto Alegre (APPOA); pesquisadora do CNPq.

E-mail: mcrispoli@terra.com.br

LUCIA ALMEIDA: gerente de desenvolvimento da MSA Consultoria em $\mathrm{RH}_{\text {; }}$ mestre pela Universidade Veiga de Almeida - RJ; formada em Psicologia pela FAMATH e pós-graduada em Economia com ênfase em Gestão Empresarial pela FGV/RJ.

E-mail: luciacsalmeida@yahoo.com.br 